\title{
Cadeia Produtiva da Moda: um Modelo Conceitual de Análise da Competitividade no Elo Confecção
}

\author{
Sandra Regina Rech
}

\section{Resumo}

Este artigo apresenta um modelo conceitual de análise da competitividade para moda, com enfoque nas micro e pequenas empresas de confecção, fruto de pesquisa qualitativa e quantitativa, do ponto de vista da abordagem; e exploratória descritiva, do ponto de vista de seus objetivos. Através da identificação dos fatores internos de competitividade e dos elementos de moda que interferem na etapa mais a jusante da cadeia produtiva, pretendeu-se avaliar a aderência de abordagem entre a práxis empresarial e o conhecimento disseminado pela academia, bem como apontar os itens relevantes para a proposição de um paradigma conceitual de análise competitiva.

Palavras-chave: Cadeia Produtiva; Moda; Competitividade.

\section{Introdução}

O potencial de crescimento de um País é afetado pela sua capacidade de gerar conhecimento, o que demanda um amplo espectro de iniciativas e reformas interconectadas. A nova configuração da competitividade sustentável prescreve uma reestruturação em termos de aparato tecnológico; gestão de pessoas e custos e de estratégias empresariais, sendo que este novo patamar competitivo passa a montante por atividades de pesquisa \& desenvolvimento, e a jusante, pela comercialização, distribuição e estratégias de marketing. A abertura do mercado global coopera para a circulação de idéias e para a procura por novidades, instigando a inovação e a criatividade, principais estratégias competitivas. O sucesso, neste novo contexto, é obtido através da geração, exploração, aplicação e comercialização do conhecimento. Portanto, 
a competitividade não está fundamentada, tão somente, nos custos, mas na natureza da competição para aspectos intangíveis tais como velocidade, inovação e design.

\section{Metodologia}

O presente texto corresponde ao resultado da tese de doutoramento Cadeia Produtiva da Moda: um modelo conceitual de análise da competitividade no elo confecção, que teve como objetivo propor um modelo conceitual de análise competitiva para moda. A pesquisa foi desenvolvida em quatro estágios: (a) coleta de dados secundários e primários; (b) aplicação do instrumento de coleta de dados; (c) análise e interpretação de dados; (d) elaboração de um modelo conceitual de análise competitiva da moda. 0 desenho metodológico adotado compreendeu a documentação indireta e direta, objetivando a reunião de informações relevantes para a compreensão da temática investigada e para a elaboração de um referencial teórico sobre a Cadeia Produtiva da Moda, Competitividade e Confecção, enfatizando seus principais indicadores econômico-produtivos e suas peculiaridades. Caracterizou-se como uma pesquisa aplicada de cunho qualitativo e quantitativo, do ponto de vista da abordagem, e exploratória descritiva, do ponto de vista de seus objetivos.

\section{Pesquisa Quantitativa}

Nesta fase, foram utilizados métodos de pesquisa survey exploratória e a população estudada foi trinta micro e pequenas confecções do município de Florianópolis (SC), sendo a amostragem censitária. A ferramenta escolhida para a coleta de dados foi um questionário estruturado e não disfarçado, composto por perguntas abertas e fechadas e aplicado por entrevista pessoal com os proprietários e/ou gerentes das empresas. Inicialmente, fez-se uma análise descritiva das informações obtidas no questionário para cada categoria independentemente. Posteriormente, foi utilizado o Teste Exato de Fisher para inferência e realização de alguns cruzamentos. 


\section{Pesquisa Qualitativa}

Na pesquisa qualitativa, a opção incidiu na forma de grupo de foco online, com a utilização da técnica Delphi, por meio de três rodadas de questionários enviadas para os respondentes por meio eletrônico. A amostra investigada foi composta por pesquisadores em áreas afins (sete integrantes das áreas de moda, design, artes e tecnologia); e, especialistas de entidades representativas para o setor (quatro elementos da FIESC; FIERGS; ABIT e ABRAVEST). A amostra foi não-probabilística intencional.

\section{Cadeia Produtiva da Moda}

A Cadeia Produtiva da Moda, através da coordenação e da integração entre as fases de produção da matéria-prima (agrícola ou química) e as fases industrial e distributiva, enceta o conceito de filière. $O$ termo, de origem francesa, significa fileira, ou seja, uma seqüência de atividades empresariais que conduzem a uma sucessiva transformação de bens, do estado bruto ao acabado ou designado ao consumo. Esta cadeia de produção é dotada de elevado grau de complementaridade e engloba diversos setores produtivos, desde as atividades manufatureiras de base até os serviços avançados de distribuição.

Atualmente, encontra-se num período de profundas transformações caracterizado pelo processo de globalização econômica, pelo deslocamento da fabricação devido aos custos operacionais, pela acirrada concorrência, pelo desenvolvimento veloz das tecnologias e sistemas de informação e por mudanças graves e complexas nas estruturas dos mercados (CPD, 2001, p. 1). Gimeno (2000) relata que a produção, a promoção, a distribuição e a criação compõem um conjunto de elementos que configuram e que devem ser gestionados para desenvolver a competitividade das empresas desta cadeia produtiva em face da contínua evolução do mercado. Atualmente, a concorrência está ocorrendo baseada na diferenciação (criatividade-qualidadepreço) e centrada na incorporação de elementos como estilo, design e moda nos produtos. 
Portanto, na Cadeia Produtiva da Moda, a hierarquização está ocorrendo de jusante a montante, do consumidor final à produção de matéria-prima. Nos países desenvolvidos, atualmente, a moda está ascendendo a nível de importância, sendo que as atividades de marketing, vendas e produção flexível adquirem relevância. Esta nova formatação da Cadeia relaciona-se com a progressiva divisão entre o tangível e o intangível, o material e o imaterial, as funções produtivas e as de valorização (LUPATINI, 2005). O autor salienta que, embora, a modernização da indústria têxtil e de vestuário por meio de ativos materiais (investimentos em máquinas, equipamentos e matérias-primas) continue a ser importante, cada vez mais não é suficiente. Esta carência acentua-se ao se perquirir a competitividade da Cadeia Produtiva da Moda como um todo e não tão somente em algumas empresas e/ou elos, uma vez que os ativos imateriais formam unicamente uma das dimensões para ganhos de competitividade sustentável da Cadeia. A moda é um instrumento eficaz para o aumento da competitividade das empresas, já que possibilita a diferenciação do produto e, conseqüentemente, da própria empresa (GIMENO, 2000).

\section{Competitividade}

O conceito de competitividade é objeto de apreensão autoral. "As diferenças resultam de bases teóricas, percepções da dinâmica industrial e mesmo ideologias diversas e têm implicações sobre a avaliação da indústria e sobre as propostas de política formuladas" (HAGUENAUER, 1989, p. 1). Podese alegar que as análises da competitividade consideram tanto os ambientes externos e internos, sejam a nível nacional ou internacional, à empresa, à esfera industrial e à situação econômica do setor produtivo.

É mister ressaltar que, devido à complexidade em explicar o conceito, "a definição de indicadores adequados para avaliar a competitividade está diretamente condicionada pela abrangência e pela profundidade com que 0 tema é tratado, e com quais objetivos" (COUTINHO \& FERRAZ, 1994, p. 459). Assim sendo, o comportamento competitivo de uma nação, indústria ou empresa é dependente de um "vasto conjunto de fatores, que pode se 
subdividido naqueles internos à empresa [empresarial], nos de natureza estrutural, pertinentes aos setores e complexos industriais, e nos de natureza sistêmica" (COUTINHO \& FERRAZ, 1994, p. 18).

Os fatores internos à empresa estão sob o comando da firma, que sobre eles retêm poder de decisão e controle. Pode-se arrolar a produtividade (custo/preço), qualidade, inovação e marketing, ou seja, as "estratégias a serem adotadas [inovação nos processos e produtos], sistemas de gestão, políticas de capacitação e treinamento [recursos humanos], investimentos em novas plantas e tecnologia [produção]" (MORAES, 2003, p. 13).

Os de natureza estrutural "apresentam-se com especificações setoriais mais nítidas, na medida em que tem sua importância diretamente relacionada ao padrão de concorrência característico de cada ramo industrial" (SCHENINI, 1999, p. 62). Ainda que não sendo totalmente contidos pela empresa, esta os influencia parcialmente: a dinâmica exclusiva da concorrência, o mercado consumidor, o grau de verticalização, a configuração da indústria e sua relação com as escalas de operação, o acesso à tecnologia, a propriedade dos meios de produção e o sistema fiscal-tributário. E, como fatores sistêmicos, podem-se citar os macroeconômicos, os político-institucionais, legais-regulatórios, infraestruturais; sociais; internacionais (mercado internacional). "São externalidades sobre as quais o poder de intervenção é pouco ou nulo" (MALDONADO, 2004, p. 4).

Coutinho \& Ferraz (1994), no Estudo da Competitividade da Indústria Brasileira, em função dos distintos setores avaliados, os classificaram em três blocos: (a) setores com capacidade competitiva; (b) setores com deficiências competitivas; e, (c) setores difusos de progresso técnico. O complexo têxtil, incluindo as indústrias têxtil, vestuário e de calçados de couro, se encontra no segundo conjunto, o de deficiências competitivas, contexto predominante na indústria brasileira. São "aqueles [setores] que têm a maior parte da produção originada de empresas pouco competitivas [...], são responsáveis pela maior parte da produção e do emprego industrial no País e são, em sua maioria, voltados para o consumo pessoal" (COUTINHO \& FERRAZ, 1994, p. 311).

Portanto, em função do exposto, neste trabalho foi utilizada uma visão dinâmica do termo competitividade conceituada pela United States 
International Trade Commission - USITC (Coutinho \& Ferraz, 1994, p. 457), e que está ao largo do desempenho de elementos como preços e custos. "Outros fatores, como a qualidade dos produtos, os serviços e as inovações do produto são vistos como instrumentos de sucesso industrial nos mercados domésticos e internacionais".

\section{Modelo Conceitual}

Desde as últimas décadas, a performance econômica brasileira foi contraproducente, seja em termos de crescimento ou distribuição de renda. "O Brasil perdeu uma oportunidade no início da década de 80 ao não aprofundar sua integração à economia mundial e às correntes de comércio", e, novamente, está se aventurando, pois permanecem as dificuldades de explorar o potencial de um estoque crescente de conhecimento global (DAHLMAN, 2006, p. 22). As estratégias para a utilização do conhecimento são indispensáveis, visando melhorar o desempenho de setores tradicionais, a exploração e desenvolvimento de oportunidades em novas áreas competitivas. O País deve avaliar a sua posição mundial e desenvolver um plano de ações para o seu progresso.

Neste contexto, "as transformações tecnológicas e de gestão exigem foco na produtividade; capacidade de adaptação e resposta ágil das empresas. É importante contar com mão-de-obra qualificada e com um sistema mais flexível de negociação no mercado de trabalho", além da remoção dos entraves competitivos que suprimem o adequado funcionamento da indústria $(\mathrm{CNI}, 2005$, p. 63). Por conseguinte, para a viabilização da competitividade são necessários ações ou programas integrados com políticas, serviços ou processos.

\section{Modelo Conceitual Proposto}

Apresenta-se, a seguir, um modelo conceitual de análise competitiva no elo confecção da Cadeia Produtiva da Moda, com ênfase nas micro e pequenas empresas de Florianópolis (SC). Foi desenhado a partir de análises qualitativa e quantitativa com empresários e com especialistas da academia, do 
governo e de áreas afins. Tem como compromisso, com a sociedade, a administração estratégica apontando para o desenvolvimento da região.

O modelo proposto é relacional, em rede, tendo como pilares de sustentação o marketing de relacionamento e a gestão estratégica. Isso implica na troca da orientação baseada em transações comerciais para uma alicerçada no relacionamento, compreendido como "as ligações formais dentro da empresa e com os participantes externos, especialmente com os fornecedores e os canais intermediários de distribuição, que permitem à empresa criar 0 valor que os clientes finais desejam" (GORDON, 2001, p. 89). A natureza deste modelo é abrangente, mas com escopo delineado, desafiador e alcançável pelas micro e pequenas empresas.

Para a obtenção da competitividade, o modelo proposto utiliza como indutores:

- Aperfeiçoamento da moda e do design: os ativos materiais são uma das dimensões para resultados reais de competitividade da indústria da moda;

- Aumento gradual da capacitação em inovação do produto de moda: "o objetivo principal reside em suprir a deficiência das empresas, principalmente pequenas e médias, que não possuam recursos (humanos e/ou financeiros) para integrar [inovação] em suas atividades" (RAULIK, 2006, p. 7);

- Melhoria da qualidade do processo e do produto de moda: O posicionamento proposto pela indústria para o Brasil é o de ser reconhecido internacionalmente por ofertar produtos competitivos, com elevados padrões de qualidade, inovação e valor agregado. "É fundamental para que o País acelere o crescimento da produção e aumente a participação no comércio global, condições essenciais para sustentar o desenvolvimento a longo prazo" (CNI, 2005, p. 15);

- Sinergia interna nas estratégias de diversificação: Para promover um crescimento gerador de empregos e com amplo espectro setorial e territorial é, fundamental, incentivar o crescimento das micro, pequenas e médias indústrias pela sua importância na economia brasileira. "Os arranjos produtivos locais e o fortalecimento das cadeias produtivas criam vantagens competitivas no setor industrial, em especial nas pequenas empresas" (CNI, 2005, p. 45-46); 
- Sinergia de alianças e acordos de cooperação com empresas concorrentes e com instituições: "qualquer ação ou programa fica enfraquecido quando isolado. Não há iniciativa forte suficiente que possa sustentar-se sem apoio externo ou sem a ligação com outros serviços" (RAULIK, 2006, p. 7);

- Mudança qualitativa da relação com fornecedores: o objetivo da indústria dever ser o desenvolvimento de uma atitude proativa de gestão estratégia, abarcando fornecedores, comunidades, órgãos competentes e demais partes interessadas, de modo a garantir a sustentabilidade de projetos, empreendimentos e produtos ao longo do seu ciclo de vida;

- Interação com usuários e consumidores: Uma empresa precisa ter conhecimentos quantitativos e qualitativos das percepções e das preferências dos clientes sobre o relacionamento que mantêm com a organização - do ponto de vista da empresa e da equipe da linha de frente, que está em contato direto com a clientela. "Tal conhecimento fornecerá à empresa as bases para que ela possa compreender e gerenciar completamente os clientes" (STONE, 2001, p. 114);

- Aperfeiçoamento da gestão em todo o processo produtivo: "a divulgação da cultura empreendedora e a valorização da atividade empresarial são essenciais para o crescimento do País. O elo de ligação é a interdependência entre empreendedorismo e inovação", tornando possível a horizontalização da exportação na Cadeia Produtiva da Moda (CNI, 2005, p. $34)$.

A reestruturação da Cadeia Produtiva da Moda, bem como algumas peculiaridades do elo confecção, colabora na instituição de oportunidades e de obstáculos à competitividade. Como entraves à competitividade, podem-se mencionar: (a) descompasso entre as dimensões das plantas industriais e o investimento necessário para aquisição de tecnologia CAD/CAM; (b) adoção incipiente de técnicas no que tange à organização da produção; (c) falta de estratégias explícitas para a exportação; (d) processo de informalização (subcontratação) da produção.

O modelo proposto busca criar condições para uma home base competitiva, através: 
- Da inter-relação entre empresa e interlocutores externos, quer dizer, através da proximidade / colaboração entre fornecedores / produtores / estilistas;

- Da concepção de empresas network, isto é, da associação da força produtiva e organizativa com respeito e conhecimento mercadológico. Utilização de mecanismos de apoio aos APLs, com foco nas micro e pequenas empresas; e,

- Da incorporação da pesquisa de conceitos de moda \& estilo, tornando possível o aumento da inovação e da economia de escopo, além de uma direção geral no sentido de produtos especializados com agregação de valor. Permite, ainda, a consolidação da identidade do produto de moda e o fomento à liderança na inovação e criatividade, incluindo conceitos de design sustentável e customização em massa.

É um modelo participativo e seus atores são os empresários, os trabalhadores, o governo e os clientes. É um consenso tripartite (indústria $X$ governo $X$ recursos humanos), estruturado em torno do cliente, exigindo mudanças essenciais para o processo existente atualmente. A empresa deve planejar e alinhar suas ações de negócios, suas comunicações, sua tecnologia e seu pessoal para sustentar o valor desejado pelo cliente.

O modelo conceitual proposto utiliza como fundamento o marketing de relacionamento, definido como o processo contínuo de identificação e criação de novos valores com clientes individuais e a partilha de seus benefícios durante toda uma vida de parceria (GORDON, 2001). Percebe-se que o marketing de relacionamento possibilita o desenvolvimento de "novos valores significativos para a empresa ao ajustar as exigências dos clientes atuais à capacidade produtiva dos bens atuais" (GORDON, 2001, p. 116). O marketing de relacionamento ratifica a organização da empresa em torno dos seus clientes e o uso de tecnologias e processos auxiliares no aperfeiçoamento do relacionamento empresa $X$ cliente e com outros atores dentro da cadeia de relacionamentos. Abrange uma cadeia de relacionamento e as ligações formais dentro da empresa e com participantes externos, sobretudo com os fornecedores e canais de distribuição, possibilitando, por parte da empresa, a criação de valor e atendimento dos desejos dos consumidores finais. 
O modelo apresentado é um modelo de administração estratégica. Pois, segundo Contador (1996, p. 149), "para enfrentar a competição atual, a empresa deve substituir a elaboração do plano estratégico tradicional por um conjunto de diretrizes. Ou seja, não há mais plano, mas há planejamento. E o processo de planejamento estratégico se converte em administração estratégica". Pode-se definir administração estratégica como "um conjunto harmônico de diretrizes flexíveis de curta duração" (CONTADOR, 1996, p. 149). Atualmente, as empresas apresentam três núcleos de preocupações: a satisfação dos clientes; a concorrência acirrada e os problemas internos envolvendo questões de produtividade, qualidade, produto, processo, fornecedores, etc..

\section{Ferramenta de Gestão do Modelo Conceitual Proposto}

Para a elaboração do modelo conceitual proposto foram seguidas as etapas do processo de construção do Balanced Scorecard: (a) tradução da visão de futuro do elo confecção da Cadeia Produtiva da Moda; (b) identificação do mote estratégico que compõe a estratégia organizacional; (c) construção de objetivos estratégicos; (d) determinação de indicadores e metas; (e) priorização de iniciativas ou programas estratégicos; (f) elaboração do plano de implementação. A utilização do BSC - Balanced Scorecard, como ferramenta de viabilização, possibilita a materialização da visão e a estratégia do elo confecção, numa dimensão interconectada, "por meio de um mapa coerente com objetivos e medidas de desempenho organizado segundo quatro perspectivas diferentes" (Kallas, 2003, p.91):

- Financeira: "Os objetivos financeiros servem de foco para as outras perspectivas do BSC. Qualquer medida deve fazer parte de uma cadeia de relações de causa e efeito que culminam com a melhoria do desempenho financeiro" (KALLAS, 2003, p. 37);

- Clientes: "Essa perspectiva permite que as empresas alinhem suas medidas essenciais de resultados relacionados aos clientes - satisfação, fidelidade, retenção, captação e lucratividade - com segmentos específicos de mercado" (KALLAS, 2003, p. 40); 
- Processos internos: Essa perspectiva é, basicamente, uma análise dos processos internos da organização. A análise sempre inclui a identificação dos recursos e das capacidades necessárias para elevar o nível interno de qualidade. Contudo, cada vez mais freqüentemente, os elos entre os processos internos da companhia e os de outras, das companhias colaboradoras, estão muito unidos, a ponto de exigirem que também sejam considerados (KALLAS, 2003, p. 44);

- Aprendizado e crescimento: A quarta e última perspectiva do Balanced Scorecard desenvolve objetivos e medidas para orientar 0 aprendizado e o crescimento organizacional [...] Os objetivos da perspectiva de aprendizagem e crescimento oferecem a infra-estrutura que possibilita a consecução de objetivos ambiciosos nas outras três perspectivas (KALLAS, 2003, p. 47).

Ao separar os elementos da estratégia em quatro dimensões, o BSC, ao mesmo tempo, funciona como uma ferramenta analítica dos grupos de interesse referentes às organizações, uma vez que especifica alguns grupos de interesse. Sendo um sistema de informação, comunicação e aprendizado, é o instrumento ideal para as organizações que têm o intento de transformar sua estratégia em ação, mediante objetivos, indicadores de performance e uma aplicação integradora. O BSC motiva melhorias não incrementais em áreas críticas como desenvolvimento de produtos, processos, clientes e mercados (KAPLAN, 1993).

A metodologia utilizada pelo Balanced Scorecard consiste nas seguintes etapas (KAPLAN, 1997):

- Mobilização dos líderes para o processo de mudança cultural;

- Tradução da estratégia e incubação do mapa estratégico, com indicadores e metas;

- Alinhamento da organização e dos processos à estratégia, com o desdobramento da estratégia;

- Motivação, conscientização e educação da conduta das pessoas rumo à estratégia;

- Monitoramento dos desempenhos, avaliação da implementação e revisão e adequação da estratégia. 


\section{Objetivos Estratégicos do Modelo Conceitual Proposto}

Para a construção dos objetivos estratégicos do BSC do modelo conceitual foram utilizados como base os resultados das pesquisas quantitativa e qualitativa deste estudo.

\section{Impulsionadores de Desempenho do Modelo Conceitual Proposto}

Os impulsionadores de desempenho estabelecem como será medido e acompanhado o sucesso de cada objetivo. Kaplan (1997) destaca que um bom Balanced Scorecard precisa ser um pacto ajustado à estratégia, entre os resultados (indicadores de ocorrência) e os impulsionadores de desempenho (indicadores de tendências). Os indicadores de tendências determinam os prováveis resultados futuros. Frezatti (2001) afiança que indicadores utilizados na gestão estratégica devem ser passíveis de mensuração durante certo espaço de tempo; flexíveis para modificações; motivadores para direcionar atividades; de fácil compreensão e passíveis de comprometimento por quem irá executar as ações.

Os impulsionadores de desempenho do modelo proposto para as micro e pequenas confecções são: (a) produtos e serviços de maior valor agregado; (b) produtos competitivos e de qualidade; (c) reconhecimento de marcas e produtos de moda; (d) produtos e serviços inovadores; (e) fomento ao crescimento do produto industrial; (f) aumento da participação das confecções do País no comércio global.

\section{Bases para Adoção do Modelo Conceitual Proposto}

Por meio da execução do modelo conceitual proposto (figura 1), pretende-se uma mudança no cenário do setor, através de ações como:

- Incentivo ao crescimento das micro e pequenas confecções;

- Promoção de um crescimento gerador de empregos; 
- Construção de uma imagem para os produtos de confecção com ênfase em suas peculiaridades inerentes - qualidade, diversidade, inovação, contemporaneidade, design e identidade cultural;

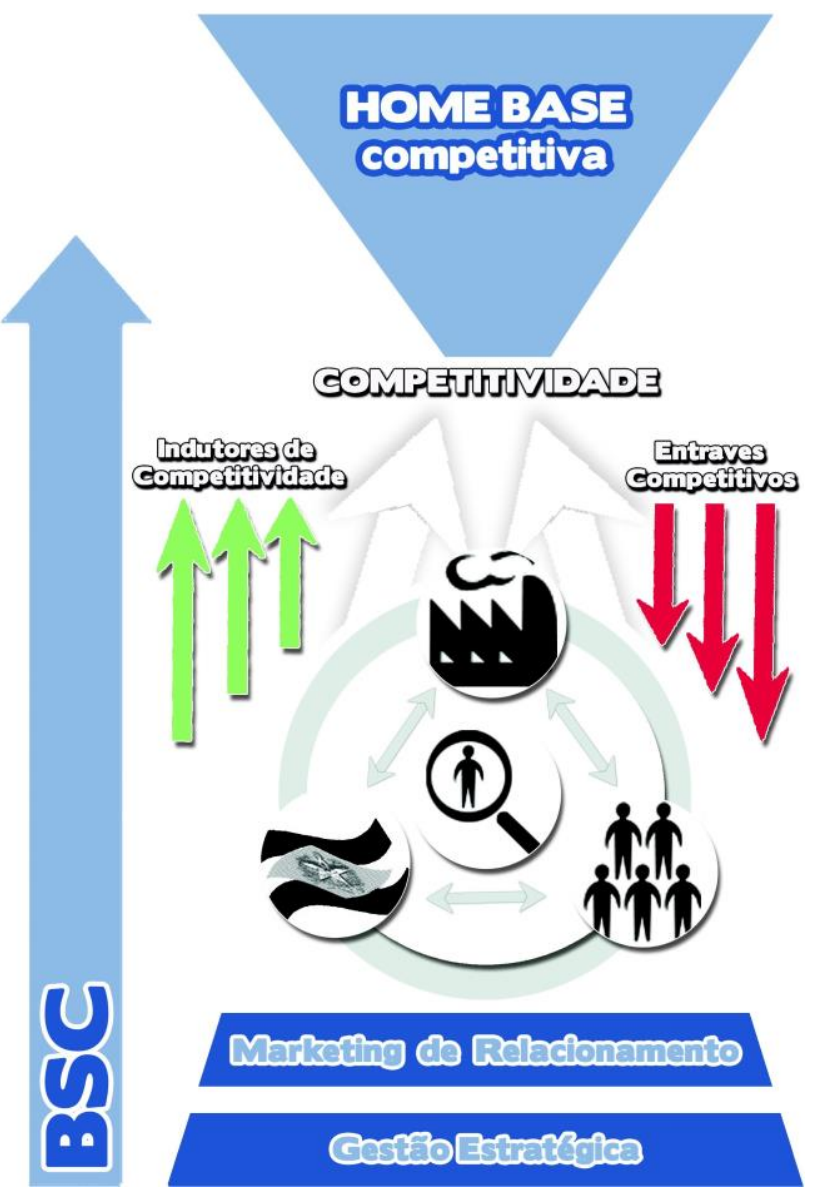

Figura 1. Modelo Conceitual Proposto

Fonte: Autora

- Elevação da produtividade como maneira sustentável de expansão da renda e da qualidade de vida da população;

- Estímulo à inovação nas empresas, ofertando produtos de qualidade e de maior valor agregado;

- Combate à informalidade e o hábito de cópia dos produtos por parte das empresas;

- Estímulo à gestão de brand nas empresas;

- Destaque aos valores intangíveis como fatores chave de competitividade; 
- Promoção do acesso à informação, por meio da implementação de centros de pesquisa \& desenvolvimento em parceria com instituições e governo;

- Implementação dos arranjos produtivos locais como suporte ao crescimento à especialização das confecções;

- Fomento à qualidade dos processos e produtos;

- Qualificação dos profissionais envolvidos;

- Incorporação do conceito de foco no cliente;

- Interface entre as empresas, instituições e os profissionais através da promoção do diálogo e da relação entre as competências da oferta e as necessidades da procura;

- Incentivo e intensificação dos investimentos em P\&D;

- Promoção da moda e do design;

- Sensibilização dos agentes econômicos para as vantagens e benefícios da utilização dos valores imateriais;

- Fortalecimento do desenvolvimento de clusters regionais de conhecimento.

Assim sendo, o modelo conceitual proposto representa uma opção para estimular o comprometimento dos setores industriais envolvidos para a materialização de uma home base competitiva. É um instrumento de articulação e organização para ações estratégicas. Significa um espectro de futuro compartilhado e uma direção estratégica de consenso. Os benefícios podem impactar positivamente toda a sociedade e sua execução será possível por um movimento amplo, fundamentado, não em ações individuais, mas, sim, em associações e alianças fortes e duradouras entre a indústria, o governo e os trabalhadores. Contudo, é interessante ressaltar que, para implementação deste modelo conceitual, é imperativa a integração com ações ou programas políticos. Isto significa que, para sua viabilização, deve haver um esforço conjunto das empresas, das instituições, dos trabalhadores e do governo na gestão do modelo. É, também, imprescindível evidenciar que as micro e pequenas empresas encontrarão algumas dificuldades para a implementação do modelo conceitual proposto sem um apoio técnico, especializado, em 
função das particularidades do modelo e da complexidade da ferramenta de gestão.

\section{Referências}

CNI. Mapa Estratégico da Indústria: 2007 - 2015. Brasília: Confederação Nacional da Indústria/DIREX, 2005.

CONTADOR, J.C. Modelo para Aumentar a Competitividade Industrial: a transição para a gestão participativa. São Paulo: Fundação Vanzolini, E.Blucher, 1996.

COUTINHO, L.; FERRAZ, J.C. Estudo da Competitividade da Indústria Brasileira. Campinas: UNICAMP, 1994.

CPD. Guia de Gestão Global de Design no Setor Têxtil. Lisboa, Portugal: Centro Português de Design, 2001.

DAHLMAN, C.; FRISCHTAK, C. Tendências da Indústria Mundial: desafios para o Brasil. Brasília: CNI, 2005.

FREZATTI, F. Contribuição para o Estudo do Market Value Added como Indicador de Eficiência na Gestão do Valor: uma análise das empresas brasileiras com ações negociadas em bolsa de valores no ambiente pós Plano Real. (Tese de livre-docência em Contabilidade e Atuária). Universidade de São Paulo, Faculdade de Economia, Administração e Contabilidade. São Paulo, SP: USP, 2001.

GIMENO, J.M.I. La Gestión del Diseño em la Empresa. Madrid, Espanha:McGraw-Hill/Interamericana de España, 2000.

GORDON, I. Marketing de Relacionamentos: estratégias e tecnologías para conquistar clientes e mantê-los para sempre. São Paulo: Fatura, 2001. 
HAGUENAUER, L. Competitividade: conceitos e medidas - uma resenha da bibliografia com ênfase no caso brasileiro. Texto para discussão no 211. Rio de Janeiro: IEI/UFRJ, ago.,1989.

KALLAS, D. Balanced Scorecard: aplicações e impactos. Um estudo com jogos de empresas. (Dissertação de Mestrado). Faculdade de Economia, Administração e Contabilidade - Universidade de São Paulo. São Paulo, SP: USP, 2003.

KAPLAN, R.S.; NORTON, D.P. Putting the Balanced Scorecard to Work. Harvard Business Review. v. 71, n‥ 5. Boston, USA: Harvard, set/out, 1993 (p. 134-147).

A Estratégia em Ação: Balanced

Scorecard. Rio de Janeiro, RJ: Campus, 1997.

LUPATINI, M. P. Setorial Preliminar: setor têxtil e vestuário. Finep - Rede DPP. Disponível em <www.finep.gov.br/portalDPP/relatorio setorial> Acesso em 14/05/2005.

MALDONADO, L.M.O; PIO, M.J. Cadeias Produtivas e Competitividade: estudos de prospecção tecnológica. In: O Futuro da Indústria. Brasília: IEL, MDIC, SENAI, 2004.

MORAES, E.A de. Inovação e Competitividade: uma proposta de redefinição da importância e escopo da inovação no modelo de estratégia competitiva baseado em competência cumulativas (Dissertação de Mestrado). Curso de Pós-Graduação da EAESP/FGV, Área de concentração: Produção e Operações. São Paulo: EAESP/FGV, 2003.

RAULIK, G. Panorama Internacional das Políticas de Promoção e Incentivo ao Design. Brasília, D.F.: MDIC, 2006. 
SCHENINI, P.C. Avaliação dos Padrões de Competitividade à Luz do Desenvolvimento Sustentável: o caso da indústria Trombini Papel e Embalagens S/A em Santa Catarina - Brasil (Tese de Doutoramento). Programa de Pós-Graduação em Engenharia de Produção - Universidade Federal de Santa Catarina. Florianópolis, SC: UFSC, 1999.

STONE, M.; WOODCOCK, N.; MACHTYNGER, L. CRM - Marketing de Relacionamentos com os Clientes. São Paulo: Futura, 2001.

\section{Abstract}

This article presents a conceptual model for the analysis of the competitiveness for fashion, with focus on micro and small enterprises of manufacture, fruit research of qualitative and quantitative in nature, in terms of the approach, exploratory and descriptive, from the point of view of its objectives. By identifying the internal factors of competitiveness and elements of fashion that interfere in step further down the production chain, it was intended to evaluate the adhesion of approach between the business practice and knowledge disseminated by the academy, as well as pointing the items relevant to the proposing of a conceptual paradigm of competitive analysis.

Key-words: Productive Chain; Fashion; Competitiveness 